\title{
Monitoring and modelling of soil-plant interactions: the joint use of ERT, sap flow and eddy covariance data to characterize the volume of an orange tree root zone
}

\author{
G. Cassiani ${ }^{1}$, J. Boaga ${ }^{1}$, D. Vanella ${ }^{2}$, M. T. Perri ${ }^{1}$, and S. Consoli ${ }^{2}$ \\ ${ }^{1}$ University of Padua, Department of Geosciences, Padua, Italy \\ ${ }^{2}$ University of Catania, Department of Agriculture, Food and Environment, Catania, Italy \\ Correspondence to: G. Cassiani (giorgio.cassiani@unipd.it)
}

Received: 10 October 2014 - Published in Hydrol. Earth Syst. Sci. Discuss.: 8 December 2014

Revised: 28 March 2015 - Accepted: 17 April 2015 - Published: 8 May 2015

\begin{abstract}
Mass and energy exchanges between soil, plants and atmosphere control a number of key environmental processes involving hydrology, biota and climate. The understanding of these exchanges also play a critical role for practical purposes e.g. in precision agriculture. In this paper we present a methodology based on coupling innovative data collection and models in order to obtain quantitative estimates of the key parameters of such complex flow system. In particular we propose the use of hydro-geophysical monitoring via "time-lapse" electrical resistivity tomography (ERT) in conjunction with measurements of plant transpiration via sap flow and evapotranspiration (ET) from eddy covariance (EC). This abundance of data is fed to spatially distributed soil models in order to characterize the distribution of active roots. We conducted experiments in an orange orchard in eastern Sicily (Italy), characterized by the typical Mediterranean semi-arid climate. The subsoil dynamics, particularly influenced by irrigation and root uptake, were characterized mainly by the ERT set-up, consisting of 48 buried electrodes on 4 instrumented micro-boreholes (about $1.2 \mathrm{~m}$ deep) placed at the corners of a square (with about $1.3 \mathrm{~m}$ long sides) surrounding the orange tree, plus 24 mini-electrodes on the surface spaced $0.1 \mathrm{~m}$ on a square grid. During the monitoring, we collected repeated ERT and time domain reflectometry (TDR) soil moisture measurements, soil water sampling, sap flow measurements from the orange tree and EC data. We conducted a laboratory calibration of the soil electrical properties as a function of moisture content and porewater electrical conductivity. Irrigation, precipitation, sap flow and ET data are available allowing for knowledge of the system's
\end{abstract}

long-term forcing conditions on the system. This information was used to calibrate a 1-D Richards' equation model representing the dynamics of the volume monitored via 3-D ERT. Information on the soil hydraulic properties was collected from laboratory and field experiments. The successful results of the calibrated modelling exercise allow for the quantification of the soil volume interested by root water uptake (RWU). This volume is much smaller (with a surface area less than $2 \mathrm{~m}^{2}$, and about $40 \mathrm{~cm}$ thick) than expected and assumed in the design of classical drip irrigation schemes that prove to be losing at least half of the irrigated water which is not taken up by the plants.

\section{Introduction}

The system made of soil, vegetation and the adjacent atmosphere is characterized by complex patterns, structures and processes that act on a wide range of timescale and space scales. While the exchange of energy and water is continuous between compartments, the pertinent fluxes are strongly heterogeneous and variable in space and time and this makes their quantification particularly challenging. Plants are known to impact the terrestrial water cycle and underground water dynamics through evapotranspiration (ET) and root water uptake (RWU). The mechanisms of water flow in the root zone are controlled by soil physics, plant physiology and meteorological factors (S. R. Green et al., 2003). The translation of plant water use strategies into physically based models of RWU is a crucial issue in eco-hydrology 
and has fundamental consequence in the understanding and modelling of atmospheric as well as soil processes. Still, no consensus exists on the modelling of this process (Feddes et al., 2001; Raats, 2007). From a conceptual point of view, two main approaches exist today, which differ in the way of predicting the volumetric rate of RWU.

A first approach expresses water transport in plants as a chain process based on a resistance law. Coupled with a three-dimensional soil water flow model, this approach leads to fairly accurate RWU models at the plant scale (Doussan et al., 2006; Schneider et al., 2010), also under water stress conditions. The limitations of these models are the cost of characterizing parameters, such as root system architecture and conductance to water flow, and their computational demand. A second approach, mostly used in soil-vegetationatmosphere transfer models, relies on "macroscopic parameters" and predicts RWU as a product of the potential transpiration rate, a spatially distributed root parameter (e.g. relative root length density), and a stress function, depending on soil water potential and a compensatory RWU function (Jarvis, 1989). The major drawback of this approach is the necessity to calibrate the macroscopic parameters, which introduces substantial uncertainties (Musters and Bouten, 2000). Note that the two approaches have indeed some formal links with each other (Couvreur et al., 2012; Javaux et al., 2008).

The complexity of RWU modelling is highly related to the uneven root distribution in the vertical and radial directions (Gong et al., 2006). This variability is partly induced by heterogeneities in the soil and localized soil compaction caused by both cultivation and irrigation patterns (Jones and Tardieu, 1998) that in turn cause heterogeneous water and nutrient distribution. Consequently, there is a clear need for the development of novel RWU modelling approaches (Couvreur et al., 2012; Feddes et al., 2001; Raats, 2007; Jarvis, 2011), as well as for accurate measurements techniques of soil water content and RWU dynamics.

In particular, soil moisture measurements are of paramount importance to calibrate RWU models. Traditionally, and especially beneath irrigated crops, soil moisture has been determined using methods such as neutron probes, time domain reflectometry (TDR) or capacitance systems. As these traditional techniques are point measurements, they do not provide sufficient information for reliable mass balance assessments; therefore, our understanding of RWU as a spatially distributed system remains fundamentally limited. In this respect the understanding of soil as a spatially heterogeneous system shares fundamental limitations with most of earth sciences. Therefore, much can be learnt looking at similar research fields.

Geophysical methods have long been established for the imaging of the soil subsurface at a variety of scales, from large-scale mining exploration (e.g. Parasnis, 1973) to the very small scale of soil mapping (e.g. Allred et al., 2008). The past 20 years, in particular, have seen the fast development of techniques that are useful in identifying structure and dynamics of the near surface, with particular reference to hydrological applications. This realm of research goes under the general name of hydro-geophysics (Binley et al., 2011; Rubin and Hubbard, 2005; Vereecken et al., 2006) and covers a wide range of applications from flow and transport in aquifers (e.g. Kemna et al., 2002; Perri et al., 2012) to the vadose zone (e.g. Daily et al., 1992), from catchment (e.g. Weill et al., 2013) and hillslope characterization (Cassiani et al., 2009a) to agriculture and eco-hydrological processes (Boaga et al., 2014; Ursino et al., 2014).

Possibly the most interesting results have been obtained when hydro-geophysical data have been coupled with distributed hydrological model predictions. The degree of integration of data and model range from trial and error calibration (e.g. Binley et al., 2002) to full data assimilation (e.g. Hinnell et al., 2010), but in all cases the availability of spatially extensive (and time intensive) data greatly improve the models' capability to identify within narrow ranges the relevant governing parameters, which in turn are of practical interest for hydrological predictions.

Relatively few hydro-geophysical applications, though, have been focussed on plant root system characterization (e.g. al Hagrey, 2007; al Hagrey and Petersen, 2011; Javaux et al., 2008; Jayawickreme et al., 2008; Werban et al., 2008), often limiting the analysis to a tentative identification of the main root location and extent. Electrical soil properties are a clear indication of soil moisture content distribution, and electrical and electromagnetic methods have been used to identify the effect of root activity (e.g. Cassiani et al., 2012; Shanahan et al., 2015). In particular, ERT has been used to characterize RWU and root systems (Garré et al., 2011; Michot et al., 2001, 2003; Srayeddin and Doussan, 2009). Amato et al. $(2009,2010)$ tested the ability of 3-D ERT for quantifying root biomass on herbaceous plants. Beff et al. (2013) used 3-D ERT for monitoring soil water content in a maize field during late growing seasons. Boaga et al. (2013) and Cassiani et al. (2015) demonstrated the reliability of the method in apple orchards.

In this paper we aim at applying hydro-geophysical techniques, with a combination of measurements and modelling, to a tree root system. This approach has, to the best of our knowledge, not been presented and analysed yet. In particular, we present the application of the time-lapse non-invasive 3-D electrical resistivity tomography (ERT) to monitor soilplant interactions in the root zone of an orange tree located in the Mediterranean semi-arid Sicilian (southern Italy) context. The subsoil dynamics, particularly influenced by irrigation and RWU, have been characterized by the 3-D ERT measurements coupled with plant transpiration through sap flow measurements. The information contained in the ERT measurements in terms of vadose zone water dynamics was exploited by comparing the field results against a 1-D vadose zone model. 
The specific goals of this paper are

1. to study the feasibility of a small-scale monitoring of root zone processes using time-lapse 3-D ERT;

2. to assess the value of the data above for a quantitative description of hydrological processes at the tens of centimetre scale;

3. to interpret these data with the aid of a physical hydrological model, in order to also derive information on the root zone physical structure and its dynamics.

\section{Site description}

The experiment was conducted in a 20 hectare orange orchard, planted with about 20 year-old trees (Citrus sinensis; cv Tarocco Ippolito) (Fig. 1). The field is located in Lentini (eastern Sicily; lat. $37^{\circ} 16^{\prime} \mathrm{N}$, long. $14^{\circ} 53^{\prime} \mathrm{E}$ ) in a Mediterranean semi-arid environment, characterized by an annual average precipitation of around $550 \mathrm{~mm}$, very dry summers and average air temperature of $7^{\circ} \mathrm{C}$ in winter and $28^{\circ} \mathrm{C}$ in summer. The site presents conditions of crop homogeneity, flat slope, dominant wind speed direction for footprint analysis and quite a large fetch which are ideal for micro-meteorological measurements. The planting layout is $4.0 \mathrm{~m} \times 5.5 \mathrm{~m}$ and the trees are drip irrigated with 4 in-line drippers per plant, spaced about $1 \mathrm{~m}$ apart, with $16 \mathrm{~L} \mathrm{~h}^{-1}$ of total discharge $\left(4 \mathrm{~L} \mathrm{~h}^{-1}\right.$ per dripper); the crop is well watered by irrigation supplied every day from May to October, with an irrigation timing of $5 \mathrm{hd}^{-1}$. The study area has a mean leaf area index (LAI) of about $4 \mathrm{~m}^{2} \mathrm{~m}^{-2}$, measured by a LAI2000 digital analyser (LI-COR, Lincoln, Nebraska, USA). The LAI values are spatially averaged and refer to the ERT measurement period (October 2013). In the specific case of a mature orange orchard, LAI values result fairly constant in time in the region of interest.

The mean PAR (photosynthetic active radiation) light interception was $80 \%$ within rows and $50 \%$ between rows; the canopy height $\left(h_{\mathrm{c}}\right)$ is $3.7 \mathrm{~m}$.

The soil characterization was performed via textural and hydraulic laboratory analyses, according to the USDA standards. The area, covered by mature orange orchards, was divided into regular grids, each having a $18 \times 32 \mathrm{~m}^{2}$ area, where undisturbed soil cores $(0.05 \mathrm{~m}$ in height and $0.05 \mathrm{~m}$ in diameter) were collected at the $0-0.05$ and $0.05-0.10 \mathrm{~m}$ depths for a total of 32 sampling points and 64 soil samples. The undisturbed soil cores were used to determine the soil bulk density, $\rho_{\mathrm{b}}\left(\mathrm{Mg} \mathrm{m}^{-3}\right)$ and the initial water content, $\theta_{i}\left(\mathrm{~m}^{3} \mathrm{~m}^{-3}\right)$, i.e. the $\theta$ value at the time of the field campaign. A total of 32 disturbed soil samples were also collected at the $0-0.05 \mathrm{~m}$ depth to determine its soil textural characteristics, using conventional methods following $\mathrm{H}_{2} \mathrm{O}_{2}$ pre-treatment to eliminate organic matter and clay deflocculation using sodium metaphosphate and mechanical agitation
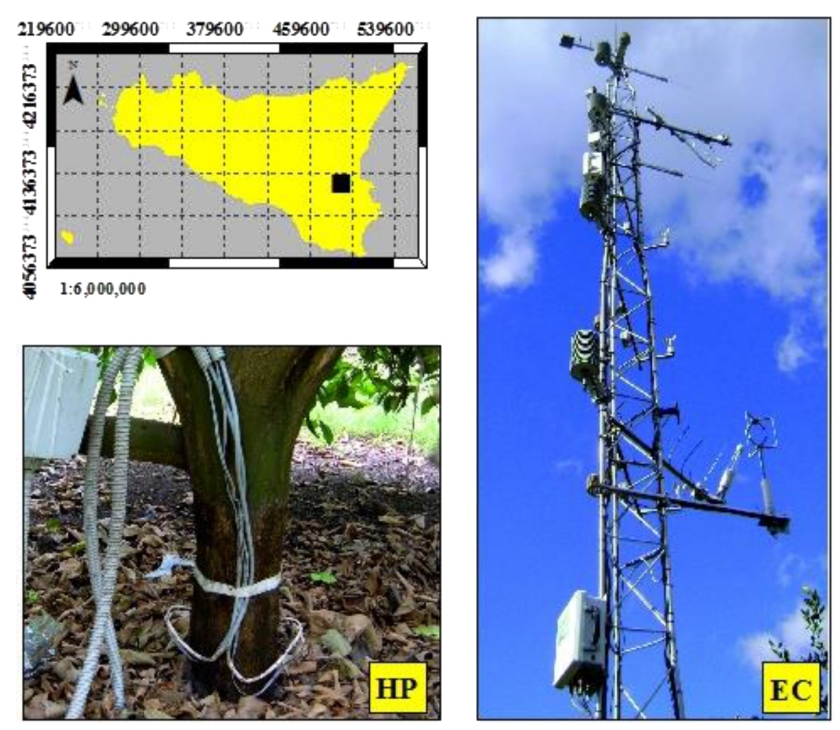

Figure 1. Bulgherano experimental site: the eddy covariance (EC) tower and a heat-pulse (HP) sap flow installation on an orange tree.

(Gee and Bauder, 1986). Three textural fractions according to the USDA standards, i.e. clay $(0-2 \mu \mathrm{m})$, silt $(2-50 \mu \mathrm{m})$ and sand $(50-2000 \mu \mathrm{m})$, were used in the study to characterize the soil (Gee and Bauder, 1986). Most soil textures (i.e. 27 out of 32) were loamy sand and the remaining textures were sandy loam.

An undisturbed soil sample was collected from the surface soil layer (0-0.05 $\mathrm{m}$ depth) at each sampling location (sample size, $N=32$ ), using stainless steel cylinders with an inner volume of $10^{-4} \mathrm{~m}^{3}$ to determine the soil water retention curve. For each sample, the volumetric soil water content at 11 pressure heads, $h$, was determined by a sandbox ( $h=0.01,0.025,0.1,0.32,0.63,1.0 \mathrm{~m})$ and a pressure plate apparatus $(h=3,10,30,60,150 \mathrm{~m})$. For each sample, the parameters of the van Genuchten $(1980, v G)$ model for the water retention curve with the Burdine (1953) condition were determined (Aiello et al., 2014).

Three soil water content profiles have been measured in the field using water content reflectometers (TDR) since 2009. Calibrated Campbell Scientific CS616 water content reflectometers $( \pm 2.5 \%$ of accuracy) were installed to monitor every $1 \mathrm{~h}$ the changes of volumetric soil water content $(\Delta \theta)$. The TDR probe installation was designed to measure soil water content variations with time in the soil volume afferent to each plant. The location of the TDR probes is considered well suited with the specific characteristics of the micro-irrigation systems used in the area and the textural soil main features. For each location the TDR equipment consists of two sensors inserted vertically at 0.20 and $0.45 \mathrm{~m}$ depth and two sensors inserted horizontally at $0.35 \mathrm{~m}$ depth, with $0.20 \mathrm{~m}$ space in between. The water content reflectometer consists of two stainless steel rods connected to a printed circuit board. When the probe rods were inserted vertically into 
the soil surface they gave an indication of the water content in the upper $20-25 \mathrm{~cm}$ of soil. The probes installed horizontal to the surface were used to detect the passing of wetting fronts of water fluxes.

The data that are discussed here (see results section) correspond to the TDR probes located at about $1.5 \mathrm{~m}$ from the orange tree we monitored with ERT.

Hourly meteorological data (incoming short-wave solar radiation, air temperature, air humidity, wind speed and rainfall) are acquired by an automatic weather station located about $7 \mathrm{~km}$ from the orchard and managed by SIAS (Agrometeorological Service of the Sicilian Region). For the dominant wind directions, the fetch is larger than $550 \mathrm{~m}$; for the other sectors the minimum fetch is $400 \mathrm{~m}$ (SE).

\section{Methodology}

\subsection{Micrometeorological measurements}

The experimental site is equipped with eddy covariance (EC) systems mounted on a micrometeorological fluxes tower (Fig. 1). Continuous energy balance measurements have been taken since 2009. In particular, net radiation $\left(R_{\mathrm{n}}, \mathrm{W} \mathrm{m}^{-2}\right)$ is measured with two CNR 1 Kipp \& Zonen (Campbell Scientific Ltd) net radiometers at a height of $8 \mathrm{~m}$. Soil heat flux density $\left(G, \mathrm{~W} \mathrm{~m}^{-2}\right)$ is measured with three soil heat flux plates (HFP01, Campbell Scientific Ltd) placed horizontally $0.05 \mathrm{~m}$ below the soil surface. Three different measurements of $G$ were selected: in the trunk row (shaded area), at onethird of the distance to the adjacent row, and at two-thirds of the distance to the adjacent row. The soil heat flux is measured as the mean output of three soil heat flux plates. Data from the soil heat flux plates are corrected for heat storage in the soil above the plates.

The air temperature and the three wind speed components are measured at two heights, 4 and $8 \mathrm{~m}$, using fine wire thermocouples ( $76 \mu \mathrm{m}$ diameter) and sonic anemometers (Windmaster Pro, Gill Instruments Ltd, at $4 \mathrm{~m}$, and a CSAT, Campbell Sci., at $8 \mathrm{~m}$ ). A gas analyzer (LI-7500, LI-COR) operating at $10 \mathrm{~Hz}$ was installed at $8 \mathrm{~m}$. The raw data are recorded at a frequency of $10 \mathrm{~Hz}$ using two synchronized data loggers (CR3000, Campbell Sci.).

The EC measurement system and the data processing followed the guidelines of the standard EUROFLUX rules (Aubinet et al., 2000). A data quality check was applied during the post processing together with some routines to remove the common errors: running means for de-trending, three angle coordinate rotations and de-spiking. Stationarity and surface energy closure were also checked (Kaimal and Finningan, 1994).

Low-frequency measurements are taken for air temperature and humidity (HMP45C, Vaisala), wind speed and direction (05103 RM Young), and atmospheric pressure (CS106, Campbell Scientific Ltd) at 4, 8 and $10 \mathrm{~m}$.
The freely distributed TK2 package (Mauder and Foken, 2004) is used to determine the first- and second-order statistical moments and fluxes on a half-hourly basis following the protocol used as a comparison reference described in Mauder et al. (2007).

\subsection{Sap flow measurements}

Heat-pulse techniques can be used to measure sap flow in plant stems with minimal disruption to the sap stream (Cohen et al., 1981; Green and Clothier, 1988; Swanson and Whitfield, 1981). The measurements are reliable, use inexpensive technology, provide a good time resolution of sap flow and they are well suited to automatic data collection and storage. Sequential or simultaneous measurements on numerous trees are possible, permitting the estimation of transpiration from whole stands of trees.

Measurements of water consumption at tree level $\left(T_{\mathrm{SF}}\right)$ have been taken using the HPV (heat pulse velocity) technique that is based on the measurement of temperature variations $(\Delta T)$, produced by a heat pulse of short duration (1$2 \mathrm{~s}$ ), in two temperature probes installed asymmetrically on either side of a linear heater that is inserted into the trunk. For HPV measurements, two $4 \mathrm{~cm}$ sap flow probe with four thermocouples embedded (Tranzflo NZ Ltd., Palmerston North, New Zealand) were inserted in the trunks of the trees, belonging to the area of the micrometeorological EC tower footprint. The probes were positioned at the north and south sides of the trunk at $50 \mathrm{~cm}$ from the ground and wired to a data logger (CR1000, Campbell Sci., USA) for heat-pulse control and measurement; the sampling interval was $30 \mathrm{~min}$. The temperature measurements are obtained by means of ultrathin thermocouples that, once the probes are in place, are located at 5, 15, 25 and $45 \mathrm{~mm}$ within the trunk.

Data have been processed according to S. Green et al. (2003) to integrate sap flow velocity over sapwood area and calculate transpiration. In particular, the volume of sap flow $\left(Q_{\text {stem }}\right)$ in the tree stem is estimated by multiplying the sap flow velocity by the cross sectional area of the conducting tissue. To this purpose, fractions of wood $\left(F_{M}=0.48\right)$ and water $\left(F_{\mathrm{L}}=0.33\right)$ in the sapwood were determined on the trees where sap flow probes were installed. Wound-effect correction (Consoli and Papa, 2013; S. Green et al., 2003; Motisi et al., 2012) was done on a per-tree basis. Crop transpiration data have been available at the study site since 2009 .

\subsection{Electrical resistivity tomography}

The key technique used to monitor the soil moisture content distribution in the volume surrounding the orange tree is ERT (e.g. Binley and Kemna, 2005). In particular, we installed a three-dimensional ERT system, consisting of 48 buried electrodes placed on 4 instrumented micro-boreholes, with 12 electrodes each (see Fig. 2). The electrodes are made of stainless steel wound around a 1 in. PVC pipe, and are spaced 
Table 1. Times of acquisitions and irrigation schedule

\begin{tabular}{|c|c|c|c|c|}
\hline Acquisition no. & Starting time (LT) & Ending time (LT) & Irrigation schedule & Date \\
\hline 0 (background) & $10: 40$ & 11:00 & \multirow{7}{*}{$\begin{array}{l}11: 30 \text { to } 16: 30 \\
41 \mathrm{~h}^{-1} \text { from } \\
\text { each dripper }\end{array}$} & \multirow{7}{*}{2 October 2013} \\
\hline 1 & $12: 00$ & $12: 20$ & & \\
\hline 2 & 13:00 & $13: 20$ & & \\
\hline 3 & $14: 15$ & $14: 35$ & & \\
\hline 4 & $15: 00$ & $15: 20$ & & \\
\hline 5 & $16: 00$ & $16: 20$ & & \\
\hline 6 & $17: 00$ & $17: 20$ & & \\
\hline 7 & $10: 15$ & $10: 35$ & \multirow{7}{*}{$\begin{array}{l}\text { 07:00 to } 12: 00 \\
41 \mathrm{~h}^{-1} \text { from } \\
\text { each dripper }\end{array}$} & \multirow{7}{*}{3 October 2013} \\
\hline 8 & 11:05 & $11: 25$ & & \\
\hline 9 & $12: 00$ & $12: 20$ & & \\
\hline 10 & $13: 00$ & $13: 20$ & & \\
\hline 11 & $14: 00$ & $14: 20$ & & \\
\hline 12 & $15: 00$ & $15: 20$ & & \\
\hline 13 & $15: 45$ & $16: 05$ & & \\
\hline
\end{tabular}

$10 \mathrm{~cm}$ along the pipe (see inset in Fig. 2); thus, the shallowest and the deepest are respectively at 0.1 and $1.2 \mathrm{~m}$ below the surface. Each electrode is made of a plate $3 \mathrm{~cm}$ wide. The boreholes are placed at the vertices of a square (with $1.3 \mathrm{~m}$ wide sides) that has the orange tree at its centre, and were inserted by percussion with the help of a pre-drilling with a smaller diameter in order to avoiding the disturbance of the electrical flow. The electrical contact is excellent for all 48 buried electrodes, as checked before each measurement. The four boreholes are water tight and in tight contact with the soil; therefore, they cannot act as pathways for preferential water infiltration. We focused our attention to an area slightly smaller than the square defined by the boreholes, in order to avoid the inevitable disturbance caused by borehole installation (slightly compacting the surrounding soil). The system is completed by 24 electrodes at the ground surface, placed along a square grid of about $0.21 \mathrm{~m}$ per side, covering the $1.3 \mathrm{~m} \times 1.3 \mathrm{~m}$ square at the surface (Fig. 3 ): this setup allows for a homogeneous coverage of the surface of the control volume. The chosen acquisition scheme was a skipzero dipole-dipole configuration, i.e. a configuration where the current dipoles and potential dipoles are both of minimal size, i.e. they consist of neighbouring electrodes, e.g. along the boreholes. This set-up ensures maximal spatial resolution (as good as the electrode spacing, at least close to electrodes themselves) provided that the signal-to-noise ratio is sufficiently high. The data quality is assessed using a full acquisition of reciprocals to estimate the data error level (see e.g. Binley et al., 1995; Monego et al., 2010). Consistently, we used for the 3-D data inversion an Occam approach as implemented in the R3 software package (Binley, 2014) accounting for the error level estimated from the data themselves. The relevant three-dimensional computational mesh is shown in Fig. 3. At each time step, about 90-95\% of the dipoles survived the $10 \%$ reciprocal error threshold. In order to build a time-consistent data set, only the dipoles surviving this error analysis for all time steps were subsequently used, reducing the number to slightly over $90 \%$ of the total. The absolute inversions were run using the same $10 \%$ error level. Time-lapse inversions were run at a lower error level equal to $2 \%$ (consistently with the literature - e.g. Cassiani et al., 2006).

We conducted repeated ERT measurements using the above apparatus for about 2 days, starting on 2 October 2013 at 11:00 LT, and ending the next day at about 16:00 LT The schedule of the acquisitions and the irrigation times is reported in Table 1. Note that the background ERT survey was acquired on 2 October at 11:00 LT before the first irrigation period was started, so that all changes caused by irrigation and subsequent ET can be referred to that instant. Note that prior to 2 October 2013, irrigation had been suspended for at least 15 days. Note also that only one dripper - with a flow of about $41 \mathrm{~h}^{-1}$ - is located at the surface of the control volume defined by the ERT set-up (Fig. 3).

\section{Results and discussion}

The paper presents results derived from both short-term (2 days) and long-term monitoring. The micrometeorological 


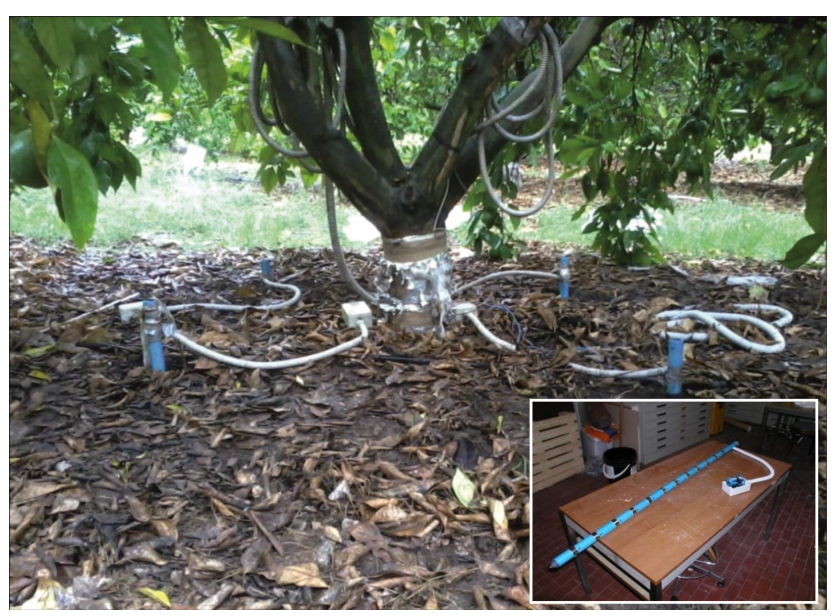

Figure 2. 3-D ERT apparatus installed around one orange tree. The system is composed of four micro-boreholes carrying 12 electrodes each (see inset) and 24 surface electrodes - see text and Fig. 3 for geometry details.

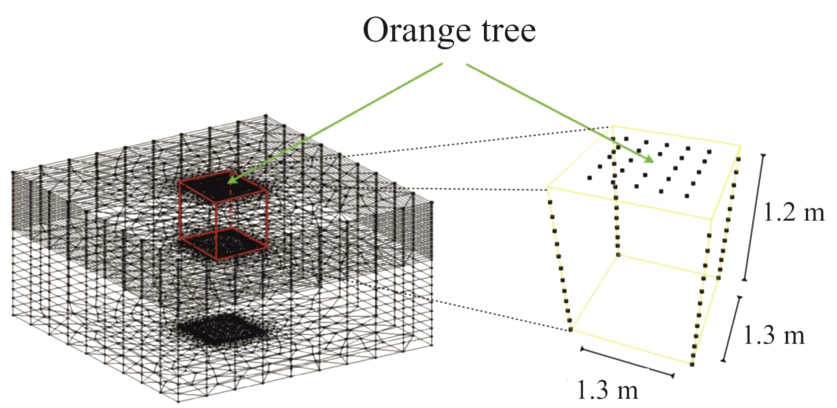

Figure 3. Electrode geometry around the orange tree and 3-D mesh used for ERT inversion.

data set (including the measurements of the energy balance components) and the sap flow data have been available since 2009. ERT measurements were carried out only during a 2day period, but the state of the system at the time of the ERT measurements clearly depends on the past forcing acting on the system. In order to fully exploit the information content of this data set, we aimed at comparing data against simulations, as much as possible in a quantitative manner.

The ERT monitoring as described in Table 1 produced two clear results:

1. The initial conditions (11:00 LT of 2 October, before irrigation starts) around the tree show a very clear difference in electrical resistivity in the top $40 \mathrm{~cm}$ of soil with respect to the rest of the volume (Fig. 4). Specifically, the resistivity of the top layer ranges around 40$50 \mathrm{Ohm} \mathrm{m}$, while the lower part of the profile is about 1 order of magnitude more conductive (about $5 \mathrm{Ohm} \mathrm{m}$ ). As no apparent lithological difference is present at $40 \mathrm{~cm}$ depth (see also laboratory results below), we attributed this difference to a marked difference in soil

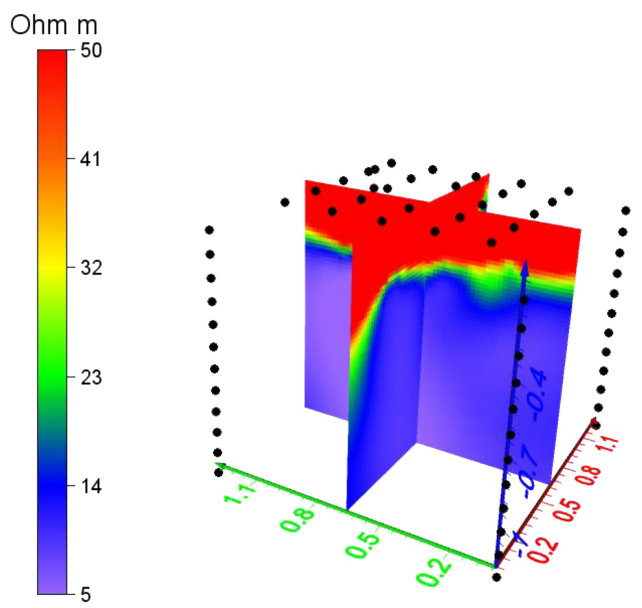

Figure 4. Cross sections of the ERT cube corresponding to the background acquisition of 2 October 2013, 11:00 LT. Note the very strong difference in electrical resistivity between the top $40 \mathrm{~cm}$ (above $50 \mathrm{Ohm}$ ) and the rest of the domain. The resistivity distribution is essentially one-dimensional with depth, with very limited horizontal variations.

moisture content. This was confirmed by all following evidence (see below).

2. The resistivity changes as a function of time, during the two irrigation periods, during the night interval, and afterwards, all show essentially the same pattern, with relatively small (but still clearly measurable) changes (Fig. 5). Two zone are identifiable: (a) a shallow zone (top $10-20 \mathrm{~cm}$ ) where resistivity decreases with respect to the initial condition, and (b) a deeper zone (20$40 \mathrm{~cm}$ ) where resistivity increases.

Qualitatively, both pieces of evidence can be easily explained in terms of water dynamics governed by precipitation, irrigation and RWU. Specifically, the shallower high resistivity zone in Fig. 4 can be correlated to a dry region where RWU manages to keep soil moisture content to minimal values, as an effect of the entire summer strong transpiration drive. The dynamics in Fig. 5, albeit small compared to the initial root uptake signal in Fig. 4, still confirm that the top $40 \mathrm{~cm}$ is home to strong root activity, to the point that irrigation cannot raise electrical conductivity of the shallow zone $(10-20 \mathrm{~cm})$ by no more than some $20 \%$, and the roots manage to make the soil even drier (with a resistivity increase by some $10 \%$ ) in the $20-40 \mathrm{~cm}$ depth layer (Fig. 5). Note that, in general, resistivity changes of the type observed here cannot be uniquely associated with soil moisture content changes, as porewater conductivity may play a key role (e.g. Boaga et al., 2013; Ursino et al., 2014). However, in the particular case at hand, care was taken to analyse the electrical conductivity of both the water used for irrigation and the porewater, purposely extracted at about $50 \mathrm{~cm}$ depth. Both waters showed an electrical conductivity value in the range of 


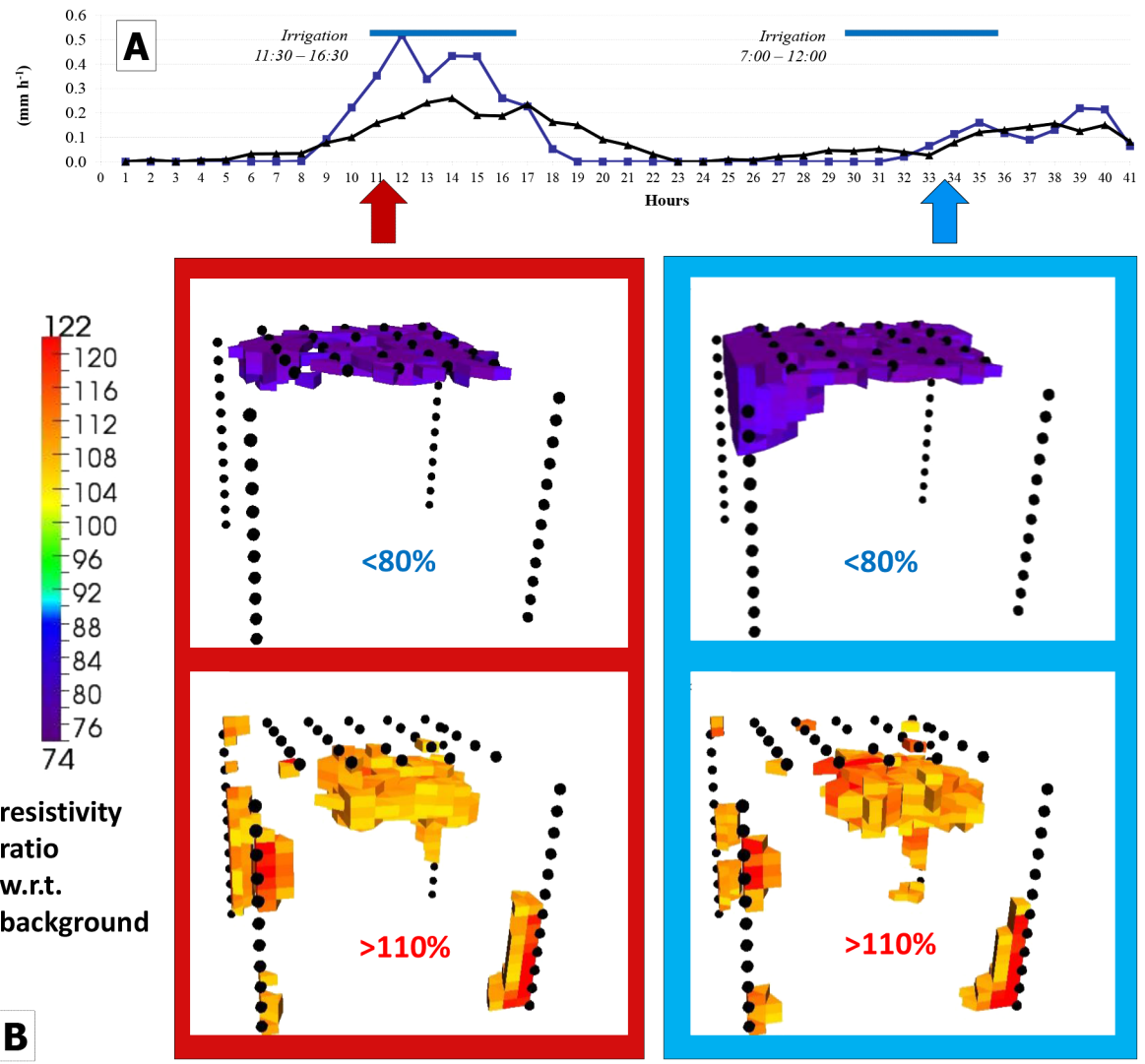

Figure 5. (a) Time series of sap flow (black line) and EC-derived total evapotranspiration (blue lines), both normalized in millimetres assuming an area of $20 \mathrm{~m}^{2}$ pertaining to the orange tree monitored with ERT. Time is given in hours from midnight of 2 October. The two irrigation periods are shown by the blue bars. (b) 3-D ERT images of resistivity change with respect to background at two selected time instants shown by the arrows in (a); the volumes corresponding to increase and decrease of resistivity above and below certain thresholds $(80$ and $110 \%$ ) are shown in separate panels, for clarity.

$1300 \mu \mathrm{S} \mathrm{cm}^{-1}$ (thus fairly high, fact that explains the overall small soil resistivity observed at the site). Therefore, in this particular case we can exclude porewater conductivity effects in the observed dynamics of the system. Once again it must be stressed that this is rather the exception than the rule.

A laboratory-based method was adopted for obtaining "unaltered" soil porewater through a column displacement technique (Knight et al., 1998). In particular, Rhizon soil moisture samplers (Cabrera, 1998) were used; they represent one of the latest developments in terms of tension samplers, where it is necessary to apply a suction to withdraw porewater with a vacuum tube (Tye et al., 2003).

The qualitative evidence above is, however, not very surprising and not particularly informative: the root activity dries the soil, this is not a discovery. Things become more interesting if we can translate the ERT data into quantitative estimates of soil moisture content, and if we can use these data to calibrate hydrological models of the root zone.

To this end, we tested Bulgherano soil samples in the laboratory to obtain a suitable constitutive relationship linking moisture content and resistivity, given the know porewater conductivity that was reproduced for the water used in the laboratory. All measurements were conducted using cylindrical Plexiglas cells equipped with a four-electrode configuration designed to allow for sample saturation and desaturation with no sample disturbance, using an air injection apparatus at one end and a ceramic plate at the opposite end. The air entry pressure of the ceramic is 1 bar; thus, during all the experiments the plate remained under full water saturation, while allowing water outflow during de-saturation. At each de-saturation step, the electrical conductivity of the sample was measured under temperature-controlled conditions using a ZEL-SIP04 impedance metre (Zimmermann et al., 2008). A completed description of the set-up is given by Cassiani et al. (2009b).

Figure 6 shows two example experimental results on samples from two different depths. Note how in a wide range of soil moisture content (roughly from 5\% to saturation) the two curves in Fig. 6 lie practically on top of each other. The same applies for all tested samples. Note also that, even though some samples show the effect of the conductivity of the solid phase (through its clay fraction), at small saturation 

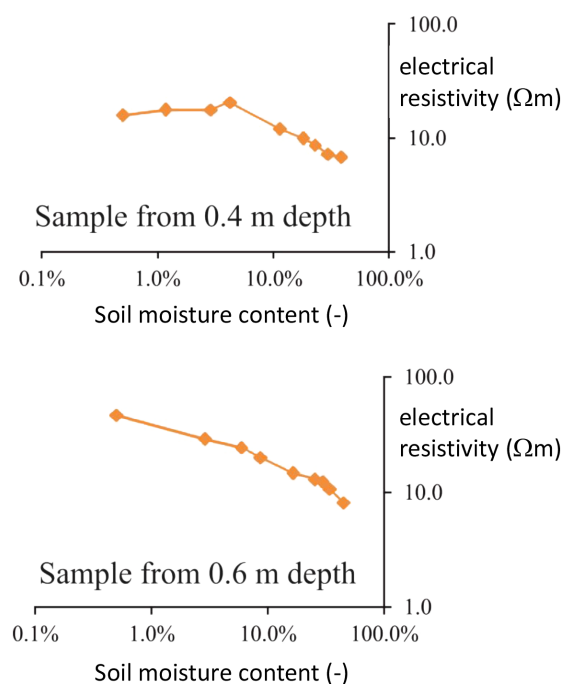

Figure 6. Experimental relationships between resistivity and moisture content determined in the lab on samples taken at two different depths at the Bulgherano site, using water having the same electrical conductivity measured in the porewater in situ.

(see sample from $0.4 \mathrm{~m}$ in Fig. 6) still the effect is small as it appears only at soil moisture smaller than $3-4 \%$. Therefore, we deemed it unnecessary to resort to constitutive laws that represent this solid phase effect, such as Waxman and Smits (1968) that has been used for similar purposes elsewhere (e.g. Cassiani et al., 2012), and we adopted the simpler formulation of Archie (1942). Consequently we translated resistivity into moisture content using the following relationship calibrated on the laboratory data, using water having the abovementioned electrical conductivity:

$\theta=\frac{4.703}{\rho^{1.12}}$,

where $\theta$ is volumetric soil moisture content (dimensionless) and $\rho$ is electrical resistivity (in Ohm m). Equation (1) allows a direct translation of the 3-D resistivity distribution to a corresponding distribution of volumetric soil moisture content. However, it has long been established that inverted geophysical data may be accompanied by enough distortion of the true physical parameter field (Day-Lewis et al., 2005) as to induce violations of elementary physical principles, such as mass balance during tracer test monitoring experiments (e.g. Singha and Gorelick, 2005). This may cause substantial problems, particular when the use of data is expected to shift from a qualitative interpretation to a quantitative use in terms of data assimilation into hydrological models. For this reason, coupled versus uncoupled approaches have been proposed and discussed (Hinnell et al., 2010) even though their superiority seems to depend on the specific problem, as the information content of data even in a traditional, inverted approach may be sufficient (Camporese et al., 2011, 2014). Indeed, the geometry we are considering here is very effec- tive to reconstruct the mass balance of irrigated water, as this comes as a quasi-one-dimensional infiltration front from the top, where, in addition, electrodes are located. The geometry is similar to the one used, e.g. Koestel et al. (2008), where mass balance was verified by comparison against very detailed TDR data collected in a lysimeter. In spite of these considerations, we decided to still limit ourselves to analysing the data variation principally as a function of depth, lumping the data horizontally by averaging estimated moisture content along two-dimensional horizontal planes. Note that the data set may lend itself to more complex analyses such as the one proposed by Manoli et al. (2014), especially if used in the context of a formal data assimilation, but we felt that one such an endeavour would exceed the scope of the current paper and deserves an ad hoc space. Note also that the ERT field evidence both in terms of background (Fig. 4) and time-lapse evolution (Fig. 5) of moisture content confirm the hypothesis that, within the control volume, the distribution of water in the soil is largely one-dimensional as a function of depth.

The data, once condensed in this manner, lend themselves more easily to a comparison with the results of infiltration modelling. We implemented a one-dimensional finite element model based on a Richards' equation solver ("Femwater" - details of this classical model are given by Lin et al., 1997), simulating the central square metre of the ERTmonitored control volume, down to a total depth of $2 \mathrm{~m}$ (much below the depth of the ERT boreholes), where we assumed that the water table is located (Dirichlet boundary condition). We applied at the top of the soil column a Neumann boundary condition consistent with the flux coming from irrigation that pertains the control volume (basically, the water coming from a single dripper). As Femwater is a 3-D simulator, the soil column is also bounded laterally by no-flow conditions, with the exception of the top $40 \mathrm{~cm}$ where we applied laterally a Neumann condition simulating the RWU (see below for details).

We considered only the central part of the ERT-controlled volume $(1 \mathrm{~m} \times 1 \mathrm{~m})$, thus excluding the regions too close to the boreholes that, even though benefitting from the best ERT sensitivity, might have been altered from a hydraulic viewpoint by the drilling and installing operations. Correspondingly we horizontally averaged the ERT data only in this central region.

A very fine vertical discretization $(0.01 \mathrm{~m})$ and time stepping $(0.01 \mathrm{~h})$ ensures solution stability. The porous medium is homogeneous along the column and parameterized according to the Van Genuchten (1980) model. The relevant parameters have been derived independently from laboratory and field measurements, the latter particularly relevant for the definition of a reliable in situ saturated hydraulic conductivity estimate. The parameters used for the simulations are residual moisture content $\theta_{\mathrm{r}}=0.0$; porosity $\theta_{\mathrm{s}}=0.54$, $\alpha=0.121 \mathrm{~m}^{-1}, n=1.6$; and saturated hydraulic conductivity $K_{\mathrm{s}}=0.002 \mathrm{~m} \mathrm{~h}^{-1}$. We acknowledge that a more complete 
sensitivity analysis concerning the impact of the individual parameters would be beneficial, but this should be performed in a complete Monte Carlo manner in order to exclude identification trade-offs between the Van Genuchten parameters, the depth of the water table (known with some uncertainty) and the fluxes from irrigation, precipitation and ET. However, we feel that this endeavour shall be conducted also with regard to the effective 3-D spatial distribution of active roots, and is currently the subject of ongoing research.

The remaining elements of the predictive modelling exercise are initial and boundary conditions. As we focused primarily our attention on reproducing the state of the system at background conditions, we set the start of the simulation at the beginning of the year (1 January 2013), and we assumed for that time a condition drained to equilibrium. Given the van Genuchten parameters we used and the depth of the water table, this corresponds to a fairly wet initial condition. We verified a posteriori that moving the initial time back of 1 year or more did not alter the predicted results at the date of interest (3 October 2013). The dynamics during the year are sufficient to bring the system to the real, much drier condition in October. The forcing conditions on the system are all known: (a) irrigation is recorded, and only one dripper pertains to the considered square metre; (b) precipitation is measured; (c) sap flow is measured. Direct evaporation from the square metre of soil around the stem is neglected, considering the dense canopy cover and the consequent limited radiation received. Only 1 degree of freedom is left to be calibrated, i.e. the volume from which the roots uptake water. Thickness of the active root zone was estimated from the time-lapse observations (Fig. 5), and fixed to the top $0.4 \mathrm{~cm}$ after checking that limiting the root uptake to the $0.2 \mathrm{~m}$ to $0.4 \mathrm{~m}$ zone would produce results inconsistent with observations in the top $0.2 \mathrm{~m}$. Therefore only the surface area of the root uptake zone remains to be estimated. We used the predictive model as a tool to identify the extent of this zone, that is of critical interest also for irrigation purposes.

Figure 7 shows the results of the calibration exercise. It is apparent that the total areal extent of the root uptake zone has a dramatic impact on the predicted moisture content profiles, as it scales the amount of water subtracted from the monitored square metre considered in the calibration. Even relatively small changes $( \pm 15 \%)$ of the root uptake area produce very different soil moisture profiles. The value that allows for a good match of the observed profile is $1.75 \mathrm{~m}^{2}$, while for areas equal to $1.5 \mathrm{~m}^{2}$ and $2 \mathrm{~m}^{2}$ the match is already unsatisfactory, leading respectively to underestimation and overestimation of the moisture content in the profile.

Another important fact that is apparent from Fig. 7 is that the estimated soil moisture in the shallow zone (roughly down to $0.4 \mathrm{~m}$ ) is very small as an effect of RWU. However, this dry zone must have a limited areal extent $\left(1.75 \mathrm{~m}^{2}\right.$, corresponding to a radius of about $0.75 \mathrm{~m}$ from the stem of the tree). Indeed this is indirectly confirmed by the soil moisture evolution measured by TDR. Figure 8 shows the TDR data

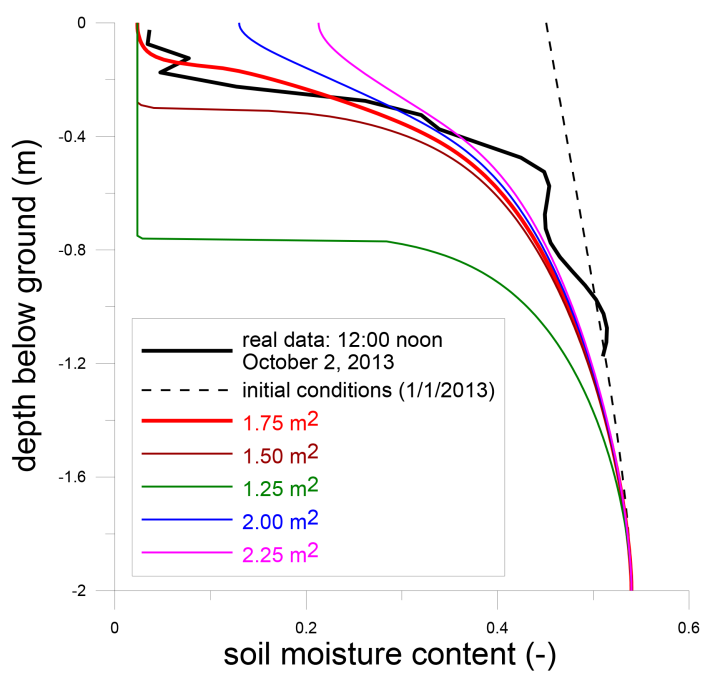

Figure 7. Results of 1-D Richards' equation simulations of the entire year 2013 up to 3 October 11:00 LT, i.e. in correspondence of the background ERT acquisition (the thick black line represents the resulting estimated moisture content profile obtained from averaging horizontally the central square metre of the ERT control volume). The different simulated curves correspond to different assumed areas of root water uptake (RWU), and show how $1.75 \mathrm{~m}^{2}$ is the area that allows one to match the observed real profile with good accuracy. Note also the high sensitivity of the results to the estimated root uptake area.

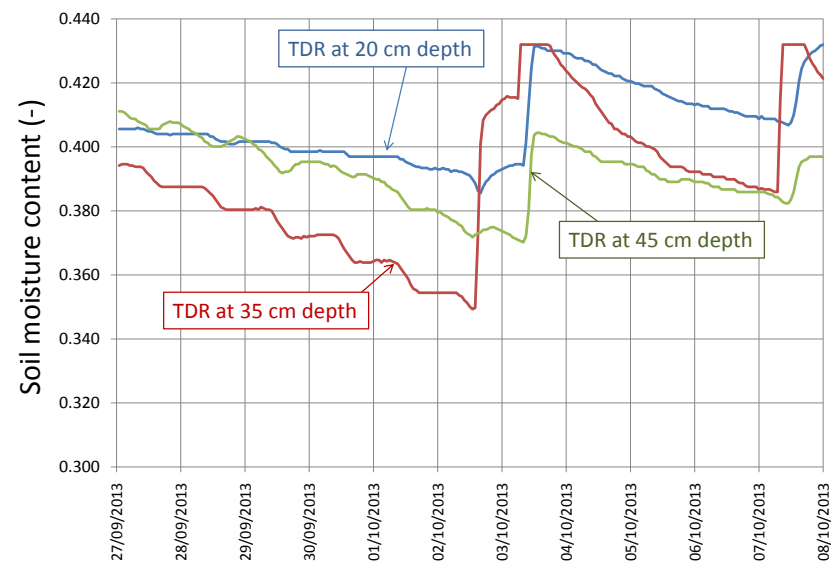

Figure 8. Moisture content time series from three TDR probes located about $1.5 \mathrm{~m}$ from the ERT-monitored tree. The signal coming from the irrigation experiment of 2 October 2013 is very clear. Before this experiment the system had been left without irrigation for about a fortnight.

from three probes located about $1.5 \mathrm{~m}$ from the monitored tree (thus outside our estimated root uptake zone). The signal coming from the irrigation experiment of 2 October 2013 is very apparent with an increase in moisture content of all three probes, located at different depths. Note that before this experiment the system had been left without irrigation for about a fortnight. The corresponding effect on the TDR data is ap- 


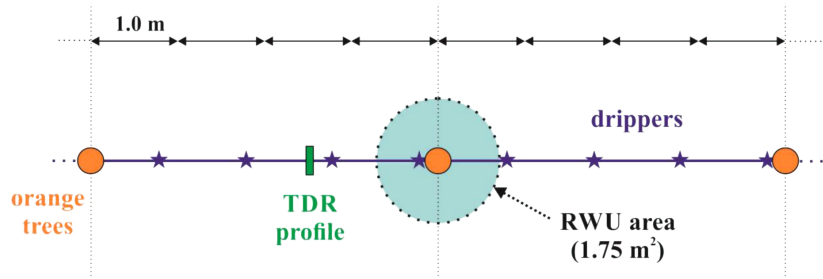

Figure 9. Scheme of the experimental field with the location of the main sensors. The radius of the root water uptake (RWU) zone, assumed to be circular, is equal to about $0.75 \mathrm{~m}$.

parent: all three probes show a decline of moisture content during the day, with pauses overnight. The decline is more pronounced in the $0.35 \mathrm{~m}$ TDR probe, that lies at a depth we estimated to be nearly at the bottom of the RWU zone, and less pronounced above $(0.2 \mathrm{~m})$ and below $(0.45 \mathrm{~m})$. Note also that the TDR probes are close to another dripper, lying outside of the ERT-controlled volume (the drippers are spaced $1 \mathrm{~m}$ along the orange trees line, with the trees about $4 \mathrm{~m}$ from each other); thus, they reflect directly the infiltration from that dripper. However, at all three depths the moisture content is much higher than measured in the ERT-controlled block closer to the tree. This can be explained with the fact that in that region the root uptake is minimal or totally absent, while the decline of moisture content in time may well be an effect of water being drawn to the root zone by lateral movement, which is induced by the very strong capillary forces exerted by the dry fine grained soil in the active root zone closer to the tree. In order to clarify the impact of these results on our understanding of the system, we show the location of the trees, of the TDR probes and of the drippers in Fig. 9, where we also sketch the best estimate for the areal extent of the RWU zone. This figure clearly highlights how critical the information provided by ERT actually is. The scale at which RWU takes place is smaller (metre scale) than expected and often assumed when it comes to designing and implementing a field monitoring system. This has dramatic consequences in terms of how reliable conclusions can be drawn if such small-scale processes are neglected. Consider, e.g. what type of conclusions could be drawn on the basis of TDR data alone (Fig. 8) in light of the field situation as depicted in Fig. 9. The single, most important message that shall be conveyed by this paper is a warning to be particularly attentive to small-scale processes in soil-plant-atmosphere interactions, even in regular agricultural landscapes.

\section{Conclusions}

Near-surface geophysics is strongly affected by both static and dynamic soil/subsoil characteristics. This fact, if properly recognized, is potentially full of information on the soil/subsoil structure and behaviour. The information is maximized if geophysical data are collected in time-lapse mode.
In the case of interactions with vegetation, its role should be properly modelled, and such models can be constrained by means (also) of geophysical data. This case study demonstrates that 3-D ERT is capable of characterizing the pathways of water distribution, and provides spatial information on root zone suction regions. The integration of modelling and data has proven, once again, a key component of this type of hydro-geophysical studies, allowing us to draw quantitative results of practical interest. In this case we had available a wealth of quantitative information about transpiration and soil moisture content that allowed the definition of the volume of soil affected by the RWU activity. This has obvious consequences for the possible improvement of irrigation strategies, as it is apparent how the monitored orange tree essentially drives water from one to two drippers out of the four in total that should pertain to its area in the plantation. This means that it is very likely that half of the irrigated water is indeed lost to deeper layers and brings no contribution to the plants. More advanced uses of this type of data are now considered, especially linking soil moisture distribution with plant physiological response and active root distribution in the soil. In the long-run studies of this type may give a fundamental contribution to our understanding of soil-plant-atmosphere interactions also in view of facing challenges coming from climatic changes.

Acknowledgements. We wish to acknowledge support from the EU FP7 project GLOBAQUA ("Managing the effects of multiple stressors on aquatic ecosystems under water scarcity") and the MIUR PRIN project 2010JHF437 "Innovative methods for water resources management under hydro-climatic uncertainty scenarios". We also wish to thank the Agro-meteorological Service of the Sicilian Region for supporting field campaigns.

Edited by: M. Vanclooster

\section{References}

Aiello, R., Bagarello, V., Barbagallo, S., Consoli, S., Di Prima, S., Giordano, G., and Iovino, M.: An assessment of the Beerkan method for determining the hydraulic properties of a sandy loam soil, Geoderma, 235-236, 300-307, 2014.

al Hagrey, S. A.: Geophysical imaging of root-zone, trunk, and moisture heterogeneity, J. Exp. Bot., 58, 839-854, 2007.

al Hagrey, S. A. and Petersen T.: Numerical and experimental mapping of small root zones using optimized surface and borehole resistivity tomography, Geophysics, 76, G25-G35, doi:10.1190/1.3545067.671, 2011.

Allred, B., Daniels, J. J., and Reza Ehsani, M.: Handbook of Agricultural Geophysics, CRC Press, USA, 432 pp., 2008.

Amato, M., Bitella, G., Rossi, R., Gomez, J. A., Lovelli, S., and Gomes, J. J. F.: Multi-electrode 3D resistivity imaging of alfalfa root zone, Eur. J. Agron., 31, 213-222, 2009. 
Amato, M., Rossi, R., Bitella, G., and Lovelli, S.: Multielectrode Geoelectrical Tomography for the Quantification of Plant Roots, Ital. J. Agron./Riv. Agron., 3, 257-263, 2010.

Archie, G. E.: The electrical resistivity log as an aid in determining some reservoir characteristics, Trans. AIME 146, 54-67, 1942.

Aubinet, M., Grelle, A., Ibrom, A., Rannik, U., Moncrieff, J., Foken, T., Kowalski, P., Martin, P., Berbigier, P., Bernhofer, C., Clement, R., Elbers, J., Granier, A., Grunwald, T., Morgenster, K., Pilegaard, K., Rebmann, C., Snijders, W., Valentini, R., and Vesala, T.: Estimates of the annual net carbon and water exchange of Europeran forests: the EUROFLUX methodology, Adv. Ecol. Res., 30, 113-175, 2000.

Beff, L., Günther, T., Vandoorne, B., Couvreur, V., and Javaux, M.: Three-dimensional monitoring of soil water content in a maize field using Electrical Resistivity Tomography, Hydrol. Earth Syst. Sci., 17, 595-609, doi:10.5194/hess-17-595-2013, 2013.

Binley, A.: R3t code, http://www.es.lancs.ac.uk/people/amb/ Freeware/R3t/R3t.htm (last access: August 2014), 2014.

Binley, A., Ramirez, A., and Daily, W.: Regularised image reconstruction of noisy electrical resistance tomography data, edited by: Beck, M. S., Hoyle, B. S., Morris, M. A., Waterfall, R. C., Williams, R. A., in: Process tomography, Proceedings of the 4th Workshop of the European Concerted Action on Process Tomography, Bergen, 6-8 April 1995, 401-410, 1995.

Binley, A. M. and Kemna, A.: DC resistivity and induced polarization methods, edited by: Rubin, Y. and Hubbard, S. S., in: Hydrogeophysics, Water Sci. Technol. Library, Ser. 50, Springer, New York, 129-156, 2005.

Binley, A. M., Cassiani, G., Middleton, R., and Winship, P.: Vadose zone flow model parameterisation using cross-borehole radar and resistivity imaging, J. Hydrol., 267, 147-159, 2002.

Binley, A. M., Cassiani, G., and Deiana, R.: Hydrogeophysics Opportunities and Challenges, Bollettino di Geofisica Teorica ed Applicata, 51, 267-284, 2011.

Boaga, J., Rossi, M., and Cassiani, G.: Monitoring soil-plant interactions in an apple orchard using 3D electrical resistivity tomography, Conference on Four Decades of Progress in Monitoring and Modeling of Processes in the Soil-Plant-Atmosphere System: Applications and Challenges, Naples, 19-21 June 2013, Proc. Environ. Sci., 19, 394-402, 2013.

Boaga, J., D’Alpaos, A., Cassiani, G., Marani, M., and Putti M.: Plant-soil interactions in salt marsh environments: Experimental evidence from electrical resistivity tomography in the Venice Lagoon, Geophys. Res. Lett., 41, 6160-6166, doi:10.1002/2014GL060983, 2014.

Burdine, N. T.: Relative permeability calculation from pore size distribution data, Trans. Am. Inst. Min. Eng., 198, 71-78, 1953.

Cabrera, R. I.: Monitoring chemical properties of container growing media with small soil solution samplers, Sci. Horticult., 75, 113119, 1998.

Camporese, M., Salandin, P., Cassiani G., and Deiana, R.: Impact of ERT data inversion uncertainty on the assessment of local hydraulic properties from tracer test experiments, Water Resour. Res., 47, W12508, doi:10.1029/2011WR010528, 2011.

Camporese, M., Cassiani, G., Deiana, R., Salandin, P., and Binley, A.: Coupled and uncoupled hydrogeophysical inversions using ensemble Kalman filter assimilation of ERT- monitored tracer test data, Water Resour. Res., accepted, doi:10.1002/2014WR016017, 2015.

Cassiani, G., Bruno, V., Villa, A., Fusi, N., and Binley, A. M.: A saline trace test monitored via time-lapse surface electrical resistivity tomography, J. Appl. Geophys., 59, 244-259, 2006.

Cassiani, G., Godio, A., Stocco, S., Villa, A., Deiana, R., Frattini, P., and Rossi, M.: Monitoring the hydrologic behaviour of steep slopes via time-lapse electrical resistivity tomography, Near Surface Geophysics, special issue on Hydrogeophysics - Methods and Processes, 475-486, doi:10.3997/1873-0604.2009013, 2009a. Cassiani, G., Kemna, A., Villa, A., and Zimmermann, E.: Spectral induced polarization for the characterization of freephase hydrocarbon contamination in sediments with low clay content, Near Surface Geophysics, special issue on Hydrogeophysics - Methods and Processes, 547-562, doi:10.3997/18730604.2009028, 2009b.

Cassiani, G., Ursino, N., Deiana, R., Vignoli, G., Boaga, J., Rossi, M., Perri, M. T., Blaschek, M., Duttmann, R., Meyer, S., Ludwig, R., Soddu, A., Dietrich, P., and Werban, U.: Noninvasive monitoring of soil static characteristics and dynamic states: a case study highlighting vegetation effects, Vadose Zone Journal, Special Issue on SPAC - Soil-plant interactions from local to landscape scale, August 2012, V.11, vzj2011.0195, doi:10.2136/2011.0195, 2012.

Cassiani, G., Boaga, J., Rossi, M., Fadda, G., Putti, M., Majone, B., and Bellin, A.: Soil-plant interaction monitoring: small scale example of an apple orchard in Trentino, North-Eastern Italy, Sci. Total Environ., in press, 2015.

Cohen, Y., Fuchs, M., and Green, G. C.: Improvement of the heatpulse method for determining sap flow in trees, Plant Cell Environ., 4, 391-397, 1981.

Consoli, S. and Papa, R.: Corrected surface energy balance to measure and model the evapotranspiration of irrigated orange orchards in semi-arid Mediterranean conditions, Irrigation Science September 2013, 31, 1159-1171, 2013.

Couvreur, V., Vanderborght, J., and Javaux, M.: A simple threedimensional macroscopic root water uptake model based on the hydraulic architecture approach, Hydrol. Earth Syst. Sci., 16, 2957-2971, doi:10.5194/hess-16-2957-2012, 2012.

Daily, W., Ramirez, A., LaBrecque, D., and Nitao, J.: Electrical resistivity tomography of vadose zone movement, Water Resour. Res., 28, 1429-1442, 1992.

Day-Lewis, F. D., Singha, K., and Binley, A. M.: Applying petrophysical models to radar travel time and electrical resistivity tomograms: Resolution-dependent limitations, J. Geophys. Res.Solid Earth, 110, B08206, doi:10.1029/2004JB003569, 2005.

Doussan, C., Pierret, A., Garrigues, E., and Pagès, L.: Water uptake by plant roots: II - Modelling of water transfer in thesoil root-system with explicit account of flow within the root system - Comparison with experiments, Plant Soil, 283, 99-117, doi:10.1007/s11104-004-7904-z, 2006.

Feddes, R. A., Hoff, H., Bruen, M., Dawson, T., de Rosnay, P., Dirmeyer, P., Jackson, R. B., Kabat, P., Kleidon, A., Lilly, A., and Pitman, A. J.: Modelling Root Water Uptake in Hydrological and Climate Models, B. Am. Meteor. Soc., 82, 2797-2809, 2001.

Garré, S., Javaux, M., Vanderborght, J., Pagès, L., and Vereecken, H.: Three-Dimensional Electrical Resistivity Tomography to 
Monitor Root Zone Water Dynamics, Vadose Zone J., 10, 412424, doi:10.2136/vzj2010.0079, 2011.

Gee, G. W. and Bauder, J. W.: Particle-size analysis, edited by: Klute, A., Methods of Soil Analysis, Part 1, Physical and Mineralogical Methods, Agronomy Monograph No. 9, 2 ed., 383-411, American Society of Agronomy/Soil Science Society of America, Madison, WI, 1986.

Gong, D., Shaozhong, K., Zhang, L., Taisheng, D., and Limin, Y.: A two-dimensional model of root water uptake for single apple trees and its verification with sap flow and soil water content measurements, Agr. Water Manage., 83, 119-129, 2006.

Green, S. R. and Clothier, B. E.: Water use of kiwifruit vines and apple trees by the heat-pulse technique, Exp. Bot., 39, 115-123, 1988.

Green, S. R., Vogeler, I., Clothier, B. E., Mills, T. M., and van den Dijssel, C.: Modelling water uptake by a mature apple tree, Austr. J. Soil Res., 41, 365-380, 2003.

Green, S., Clothier, B., and Jardine B.: Theory and Practical Application of Heat Pulse to Measure Sap Flow, Agronomy Journal; Nov/Dec 2003, 95, ProQuest Agricult. J., p. 1371, 2003.

Hinnell, A. C., Ferré, T. P. A., Vrugt, J. A., Huisman, J. A., Moysey, S., Rings, J., and Kowalsky, M. B.: Improved extraction of hydrologic information from geophysical data through coupled hydrogeophysical inversion, Water Resour. Res., 46, W00D40, doi:10.1029/2008WR007060, 2010.

Jarvis, N. J.: A simple empirical-model of root water-uptake, J. Hydrol., 107, 57-72, doi:10.1016/0022-1694(89)90050-4, 1989.

Jarvis, N. J.: Simple physics-based models of compensatory plant water uptake: concepts and ecohydrological consequences, Hydrol. Earth Syst. Sci., 15, 3431-3446, doi:10.5194/hess-15-34312011, 2011.

Javaux, M., Schroder, T., Vanderborght, J., and Vereecken, H.: Use of a Three- Dimensional Detailed Modeling Approach for Predicting Root Water Uptake, Vadose Zone J., 7, 1079-1088, 2008.

Jayawickreme, H., Van Dam, R., and Hyndman, D. W.: Subsurface imaging of vegetation, climate, and root-zone moisture interactions, Geophys. Res. Lett., 35, L18404, doi:10.1029/2008GL034690, 2008.

Jones, H. G. and Tardieu, F.: Modelling water relations of horticultural crops: a review, Sci. Hortic.-Amsterdam, 74, 21-46, 1998.

Kaimal, J. C. and Finnigan, J.: Atmospheric Boundary Layer Flows: Their Structure and Measurement, Oxford University Press, New York, 255-261, 1994.

Kemna, A., Vanderborght, J., Kulessa, B., and Vereecken, H.: Imaging and characterisation of subsurface solute transport using electrical resistivity tomography ERT and equivalent transport models, J. Hydrol., 267, 125-146, 2002.

Koestel J., Kemna, A., Javaux, M., Binley, A., and Vereecken, H.: Quantitative imaging of solute transport in an unsaturated and undisturbed soil monolith with 3-D ERT and TDR, Water Resour. Res., 44, W12411, doi:10.1029/2007WR006755, 2008.

Knight, B. P., Chaudri, A. M., McGrath, S. P., and Giller, K. E.: Determination of chemical availability of cadmium and zinc in soils using inert soil moisture samplers, Environ. Poll., 99, 293298, 1998.

Lin, H. J., Richards, D. R., Talbot, C. A., Yeh, G.-T., Cheng, J., and Cheng, H.: FEMWATER: a three-dimensional finite element computer model for simulating density-dependent flow and transport in variably saturated media, US Army Corps of Engi- neers and Pennsylvania State University, Technical Report CHL97-12, 1997.

Manoli, G., Bonetti, S., Domec, J. C., Putti, M., Katul, G., and Marani, M.: Tree root systems competing for soil moisture in a 3D soil-plant model, Adv. Water Res., 66, 32-42, doi:10.1016/j.advwatres.2014.01.006, 2014.

Mauder, M. and Foken, T.: Documentation and instruction manual of the eddy covariance software package TK2. Universität Bayreuth, Abt. Mikrometeorologie, Arbeitsergebnisse, http:// www.geo.unibayreuth.de/mikrometeorologie/ARBERG (last access: August 2014), 26-44, 2004.

Mauder, M., Oncley, S. P., Vogt, R., Weidinger, T., Ribeiro, L., Bernhofer, C., Foken, T., Kosiek, W., De Bruin, H. A. R., and Liu, H.: The energy balance experiment EBEX-2000. Part II. Intercomparison of eddy-covariance sensors and post-field data processing methods, Bound.-Layer Meteorol., 123, 29-54, doi:10.1007/s10546-006-9139-4, 2007.

Michot, D., Dorigny, A., and Benderitter Y.: Determination of water flow direction and corn roots-induced drying in an irrigated Beauce CALCISOL, using electrical resistivity measurements, Comptes Rendus De L'Academie Des Sciences Serie Ii Fascicule a-Sciences De La Terre Et Des Planetes, 332, 29-36, 2001.

Michot, D., Benderitter, Y., Dorigny, A., Nicoullaud, B., King, D., and Tabbagh, A.: Spatial and temporal monitoring of soil water content with an irrigated corn crop cover using surface electrical resistivity tomography, Water Resour. Res., 39, p. 1138, 2003.

Musters, P. A. D. and Bouten, W.: A method for identifying optimum strategies of measuring soil water contents for calibrating a root water uptake model, J. Hydrol, 227, 273-286, 2000.

Monego, M., Cassiani, G., Deiana, R., Putti, M., Passadore, G., and Altissimo, L.: Tracer test in a shallow heterogeneous aquifer monitored via time-lapse surface ERT, Geophysics, 75, WA61WA73, doi:10.1190/1.3474601, 2010.

Motisi, A., Consoli, S., Rossi, F., Minacapilli, M., Cammalleri, C., Papa, R., Rallo, G., and D'urso, G.: Eddy covariance and sap flow measurement of energy and mass exchange of woody crops in a Mediterranean environment, Acta Horticult., 951, 121-127, 2012.

Parasnis, D. S.: Mining geophysics, Elsevier Scientific Pub. Co., 395 pp., 1973.

Perri, M. T., Cassiani, G., Gervasio, I., Deiana, R., and Binley, A. M.: A saline tracer test monitored via both surface and cross-borehole electrical resistivity tomography: comparison of time-lapse results, J. Appl. Geophys., 79, 6-16, doi:10.1016/j.jappgeo.2011.12.011, 2012.

Raats, P. A. C.: Uptake of water from soils by plant roots, Transp. Porous. Med., 68, 5-28, 2007.

Rubin, Y. and Hubbard, S. S. (Eds.): Hydrogeophysics, Springer, Dordrecht, the Netherlands, 523 pp., 2005.

Schneider, C. L., Attinger, S., Delfs, J.-O., and Hildebrandt, A.: Implementing small scale processes at the soil-plant interface - the role of root architectures for calculating root water uptake profiles, Hydrol. Earth Syst. Sci., 14, 279-289, doi:10.5194/hess14-279-2010, 2010.

Shanahan, P. W., Binley, A., Whalley, W. R., and Watts, C. W.: The use of electromagnetic induction to monitor changes in soil moisture profiles beneath different wheat genotypes, Soil Sci. Soc. Am. J., 79, 459-466, doi:10.2136/sssaj2014.09.0360, 2015. 
Singha, K. and Gorelick, S. M.: Saline tracer visualized with three dimensional electrical resistivity tomography: Field-scale spatial moment analysis, Water Resour. Res., 41, W05023, doi:10.1029/2004WR003460, 2005.

Srayeddin, I. and Doussan, C.: Estimation of the spatial variability of root water uptake of maize and sorghum at the field scale by electrical resistivity tomography, Plant Soil, 319, 185-207, doi:10.1007/s11104-008-9860-5, 2009.

Swanson, R. H. and Whitfield, D. W.: A numerical analysis of heat pulse velocity theory and practice, J. Exp. Bot., 32, 221-239 1981.

Tye, A. M., Woung, S. D., Crout, N. M. J., Zhang, H., Preston, S., Barbosa-Jefferson, V. L., Davison, W., McGrath, S. P., Paton, G. I., Kilham, K., and Resende, L.: Predicting the activity of $\mathrm{Cd}^{2+}$ and $\mathrm{Zn}^{2+}$ in soil pore water from the radio-labile metal fraction, Geochim. Cosmochim. Acta, 67, 375-385, 2003.

Ursino, N., Cassiani, G., Deiana, R., Vignoli, G., and Boaga, J.: Measuring and modeling water-related soil-vegetation feedbacks in a fallow plot, Hydrol. Earth Syst. Sci., 18, 1105-1118, doi:10.5194/hess-18-1105-2014, 2014.

Van Genuchten, M. T.: A closed form equation for predicting the hydraulic conductivity of unsaturated soils, Soil Sci. Soc. Am. J., 44, 892-898, 1980.
Vereecken, H., Binley, A., Cassiani, G., Kharkhordin, I., Revil, A., and Titov, K.: Applied Hydrogeophysics, Springer-Verlag, Berlin, 1-8, 2006.

Waxman, M. H. and Smits L. J. M.: Electrical conductivities in oilbearing shaly sands, Soc. Petr. Eng. J., 8, 107-122, 1968.

Weill, S., Altissimo, M., Cassiani, G., Deiana, R., Marani, M., and Putti, M.: Saturated area dynamics and streamflow generation from coupled surface-subsurface simulations and field observations, Adv. Water Resour., 59, 196-208, doi:10.1016/j.advwatres.2013.06.007, 2013.

Werban, U., al Hagrey, S. A., and Rabbel, W.: Monitoring of root-zone water content in the laboratory by $2 \mathrm{D}$ geoelectrical tomography, J. Plant Nutr. Soil Sci., 171, 927-935, doi:10.1002/jpln.200700145, 2008.

Zimmermann, E., Kemna, A., Berwix, J., Glaas, W., Münch, H. M., and Huisman, J. A.: A high-accuracy impedance spectrometer for measuring sediments with low polarizability, Meas. Sci. Technol., 19, 105603, doi:10.1088/0957-0233/19/10/105603, 2008. 